BLS 33, No 1 2007. DOI: http://dx.doi.org/10.3765/bls.v33i1.3534

(published by the Berkeley Linguistics Society and the Linguistic Society of America)

\title{
Laughing Our Heads Off: When Metaphor Constrains Aspect*
}

JAUME MATEU and M. TERESA ESPINAL

Universitat Autònoma de Barcelona

\section{Aspect in Idiomatic Constructions}

It has been claimed in the Distributed Morphology framework that aspectuality of verbal phrases cannot be altered in idiomatic contexts (Marantz 1997, McGinnis 2002, 2005). For example, McGinnis (2002:667) points out that it should not be surprising that the following idiomatic examples in (1), which are representative of the familiar Vendlerian classes turn out to preserve the aspectuality associated to their literal interpretations:

(1) a. States (have bigger fish to fry; take the cake)

b. Activities (beat around the bush; push one's luck)

c. Accomplishments (run X into the ground; climb the ladder of success)

d. Achievements (drop the ball; kick the bucket)

McGinnis (2005:9) goes further by claiming that "there is still no evidence that an idiomatic phrase can have an aspectual interpretation that is incompatible with its syntactic structure".

In this paper, we take issue with this radical position by showing how metaphor can change the aspectual interpretation "compatible with its syntactic structure". In order to show this, we will be using some interesting examples that fall into the class described as fake resultatives by Jackendoff $(1997,2002)$ and Glasbey $(2003,2005)$. Interestingly, these authors have pointed out that these constructions have an aspectual reading different from true resultatives: for example, compare the telic resultative constructions in (2), associated to literal eventualities, with the atelic ones in (3), associated to idiomatic ones.

\footnotetext{
* We want to express our gratitude to the BLS audience for many comments and suggestions. We also wish to acknowledge financial support from the Spanish Ministerio de Educación y Ciencia (grants HUM2006-13295-C02-01 and HUM2006-13295-C02-02), and the Generalitat de Catalunya - DGR (grant 2005SGR-00753).
} 
(2) a. The audience laughed the actor off the stage in/*for ten seconds.

b. She worked the splinter out of her finger in/*for ten seconds.

(3) a. John laughed his butt off all day long/*in ten minutes.

b. John worked his guts out all day long/*in ten minutes.

The main goal of this paper is to show that fake resultatives can be conceptually associated with durative activities, not because of Jackendoff's $(1997,2002)$ or Glasbey's $(2003,2005)$ lexical stipulations (see section 2), but rather because of regular metaphorical modes of thought that are dynamically activated in the process of idiom comprehension (Gibbs 1994, 1995, Lakoff 1993, Lakoff and Johnson 1999). In particular, as shown in section 3, we claim that the atelic interpretation is driven by the activation of the complex metaphor AN INTENSE ACTIVITY IS AN EXCESSIVE DETACHMENT OF A BODY PART, which is a subcase of AN INTENSE ACTIVITY IS AN EXCESSIVE CAUSED CHANGE OF LOCATION/STATE.

\section{Two Accounts of Fake Resultatives}

In this section, we review two previous accounts that assume that the aspectual meaning (in particular, the atelic or process interpretation) drawn from the semiidiomatic constructions in (3) follows from or relates to some unmotivated lexical stipulations: see Jackendoff $(1997,2002)$ and Glasbey (2003), respectively. We hold that idioms cannot be simply taken as non-compositional, and idiosyncratic. Rather we assume that their linguistic interpretation is no different from that of non-idiomatic constructions, and - in order to account for the atelic interpretation involved in apparent resultative constructions like those in (3) - we put forward the hypothesis (cf. Mateu and Espinal 2007) that the interpretation 'to excess' is obtained at the output of various metaphorical and metonymic conceptual processes that apply non-systematically in idiom comprehension (Gibbs 1995). Accordingly, the relevant point is not whether the supposed stipulation (or convention, as we prefer to call it here) exists, but rather whether it can be motivated or not. In contrast to Jackendoff's and Glasbey's unmotivated analyses, we will show that the relevant motivation whereby an atelic interpretation is involved in (3) is to be related to Lakoff \& Johnson's (1999) theory of conceptual metaphors (see section 3 ).

\subsection{Jackendoff $(1997,2002)$}

According to Jackendoff, the idioms in (3) form a class of constructional idioms (CI), in the sense that they show a syntactic configuration whose structure contributes semantic content above and beyond that contained in the constituent lexical items. More specifically, he claims that the data in (3) instantiates a family of idiomatic intensifiers that use the same syntax as the resultative. In other words, this class of CI corresponds to an idiomatic specialization of the resultative construction. 
In particular, he claims that the constructions in (3) are listed in the lexicon as VP idioms: see (4) and (5) for his informal representations, drawn from Jackendoff (1997:554) and Jackendoff (2002:173), respectively. The construction itself has a VP syntactic structure in which the NP + PRT are lexically fixed, and the V is a free variable. At the level of conceptual structure the schemas in (4a) and (5a) are claimed to be interpreted with an intensive adverbial force (i.e., intensely, excessively), associated with the action denoted by the verb. The NP plus the particles out/off form a class of idiomatic intensifiers that, somewhat unexpectedly, do not carry typical resultative semantics. Crucially, notice that the association between the syntactic part in $(4 a) /(5 a)$ and the interpretive one in $(4 b) /(5 b)$ is merely stipulated, and no motivation is provided for such a stipulation.

$$
\begin{aligned}
& \text { a. [vp V [bound pronoun]'s head off] } \\
& \text { b. 'V intensely' }
\end{aligned}
$$

$$
\text { a. [vp V NP PRT]: V pro }{ }_{e} \text { 's head / butt off, V pro's 's heart out }
$$

b. 'V excessively'

Adopting Jackendoff's (2002) Parallel Architecture framework, Cappelle (2005:48) provides a more formal representation in (6). In particular, notice that the Jackendovian semantic/conceptual representation in (6b) contains a Degree expression which is directly associated to the NP and Prt via two subindices: $6+2$, respectively. Indeed, we will argue that such a direct association prevents the relevant motivation from being properly captured.

a. Syntactic structure

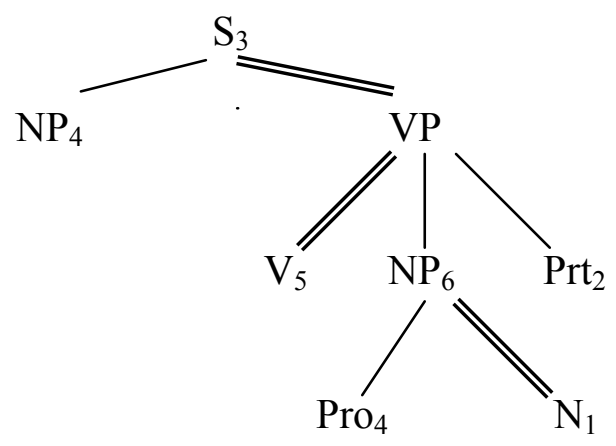


b. Semantic (conceptual) structure

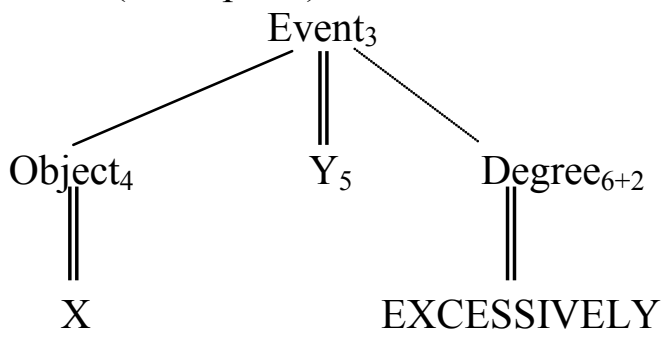

More interestingly, Jackendoff (1997:552) points out that a class of fake reflexive resultatives exists in English that show a similar intensive adverbial force, linguistically expressed by means of an AP or a PP that idiomatically mean excessively:

a. Dean laughed/danced himself crazy/silly.

b. Dean laughed/danced himself to death/to oblivion.

Concerning the aspectual meaning involved in (7), Jackendoff (1997:552) makes the interesting observation that "the expressions with crazy and silly can be used telically or atelically; those with to prefer to be telic": cf. (8). In contrast, he points out (Jackendoff 1997:551) that the abovementioned expressions with out/off-particles (as well as the V up a storm construction) can only be interpreted with an atelic reading: $\mathrm{cf}$. (9).

a. Dean laughed/danced himself crazy/silly for/in an hour.

b. Dean laughed/danced himself to death/to oblivion in/??for an hour.
a. Sue worked her butt off for/*in an hour.
b. Harry cooked up a storm for/*in an hour.
c. The frog sang his heart out for the whole night $/ *$ in a night.

To sum up, it is important to notice that under Jackendoff's architecture a constructional idiom is a special kind of phrasal lexical item, whose meaning is learnable in the same way word meanings are learned; therefore, the fact that different phrases that idiomatically mean intensely/excessively have different aspectualities must be attributed to the fact that SS-CS correspondences have to stipulate when a given SS corresponds to a telic CS (e.g. time-away construction), an atelic one (e.g. V up a storm, V NP out/off), or to both (e.g. laugh himself silly). In section 3 we will show that the aspectual meaning of this construction is activated by salient conceptual metaphors.

\subsection{Glasbey $(2003,2005)$}

Glasbey $(2003,2005)$ mainly focuses on the fact that fake resultatives like those in (3) and (9) show non-compositionality of aspect (contra McGinnis 2002, 2005), since the aspectual class conveyed by the idiomatic interpretation is an 


\section{Laughing Our Heads Off}

activity, a kind of eventuality that should be contrasted with the literal interpretation, which gives rise to an accomplishment. According to her, whereas literal eventualities have a natural endpoint and a gradual patient, there is usually no gradual patient property in the idiomatic eventuality involved in (3) and (9), unless one can imagine such a natural end point and some homomorphism can be identified between the syntactic components and certain properties of the idioms's components. Thus, her example in (10a) is partially accepted and can be submitted to the accomplishment test in $(10 \mathrm{~b})$, because a counterpart exists in the idiomatic domain (i.e. pains, feelings, thoughts, etc.) to the body part in the domain of literal interpration (i.e. heart).

(10) a. ?Patsy poured her heart out in two hours, on the phone to her sister.

b. It took Patsy two hours to pour her heart out, on the phone to her sister.

According to Glasbey (2005:5), what is characteristic about the class of idioms under the present study is that it corresponds to "a construction which describes an accomplishment under a literal interpretation and an activity under an idiomatic interpretation". She claims that idioms which do not show compositionality of aspect, tentatively identified with Nunberg, Sag, and Wasow's (1994) so-called idiomatic phrases, should best be regarded as being listed as full phrases in the lexicon with their aspectual information attached. Glasbey concludes that it is possible to view aspect as being compositional in at least some idioms (e.g. Nunberg, Sag, and Wasow's idiomatically combining expressions), while at the same time allowing for the result of the aspectual composition to be different in the idiomatic and the literal cases. The problem still is that, under her approach, no motivation is given to the empirical fact that the idioms exemplified in (3) and (9) are aspectually interpreted as activities. This is merely stipulated.

In the next section, we show that (i) Jackendoff's $(1997,2002)$ observation that the set of idioms in (3) and (9) are interpreted as "V excessively" and (ii) Glasbey's $(2003,2005)$ claim that they are interpreted as activities (but not as accomplishments) both can be motivated, if one assumes that regular metaphorical modes of thought are dynamically activated in the process of idiom comprehension (cf. Gibbs 1994f, Lakoff and Johnson 1999, among others).

\section{An Alternative Account: When Metaphor Constrains Aspect}

Before dealing with so-called fake resultatives and showing how the relevant metaphor involved can be argued to constrain their aspect, it will be useful to show how true resultatives have been analyzed within a particular cognitive framework that assumes Lakoff \& Johnson's theory of conceptual metaphors: for our present purposes, here we will be using Goldberg's (1995) Construction Grammar-based informal analysis of the resultative construction (e.g., (11b)), which is regarded as a metaphorical extension of the so-called caused-motion construction (e.g., (11a)). She represents the relation between the two constructions as in (12). Basically, according to Goldberg (1995:84f), the resultative 


\section{Jaume Mateu \& M. Teresa Espinal}

construction is a metaphorical extension of the central sense of the caused-motion construction, which is associated with the semantics " $\mathrm{X}$ CAUSES $\mathrm{Y}$ to MOVE Z”.

(11) a. Joe kicked the bottle into the yard.

b. Joe kicked Bob black and blue.

Goldberg’s (1995:88) Construction Grammar analysis

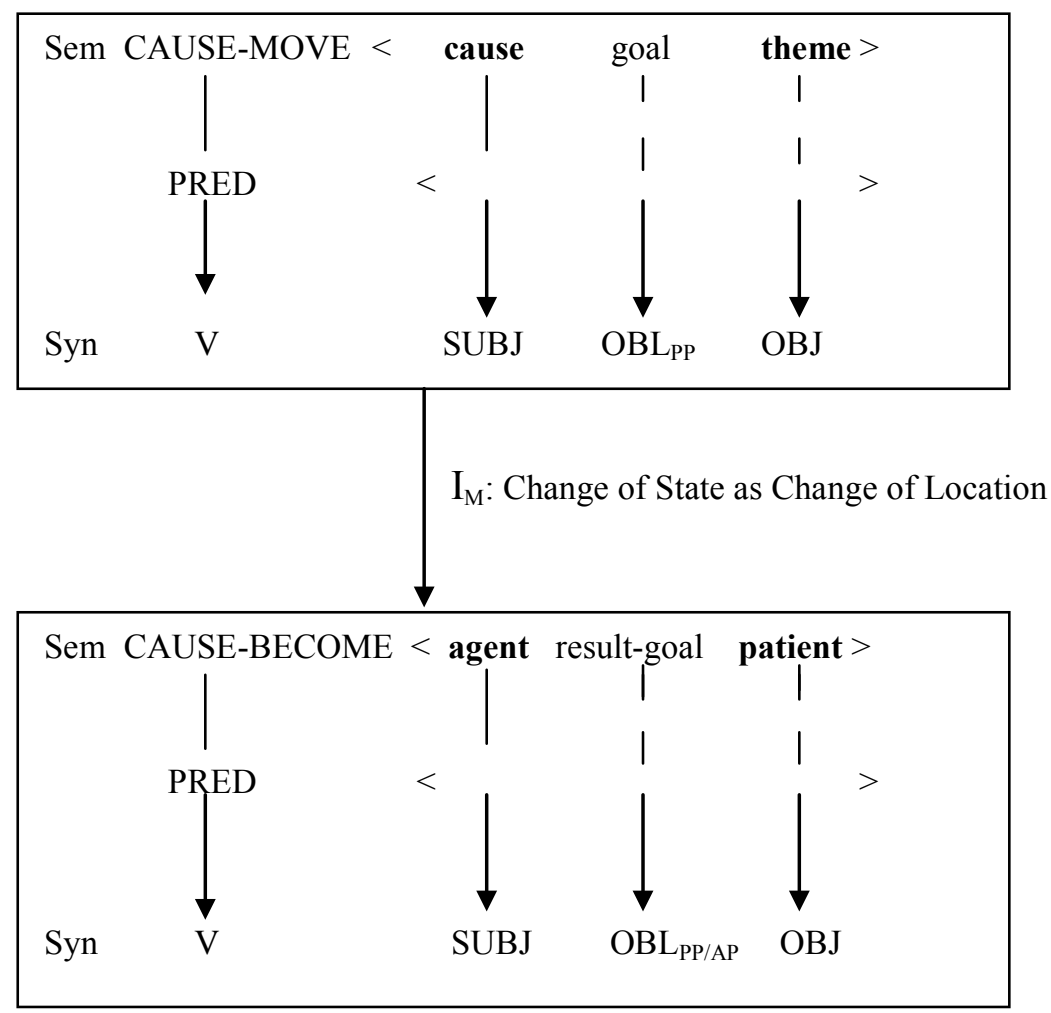

Notice that the intervention of the well-known metaphor Changes of State are Changes of Location is depicted in (12) via the metaphorical extension inheritance link $I_{M}$.

The metaphor -in this case, Change of State as Change of Location- accounts for the relation between the semantics of the two constructions. The syntactic specifications of the metaphorical extension are inherited from the caused-motion construction.

(Goldberg 1995:88-89)

To put it in Lakoff \& Johnson's (1999:52-53) terms, there are three primary metaphors involved in the resultative construction, the ones in (13).

\section{a. States are Locations}




\section{Laughing Our Heads Off}

Subjective Judgment: A subjective state

Sensoriomotor Experience: Being in a bounded region of space

Primary experience: Experiencing a certain state as correlated with a certain location (e.g., being cool under a tree, feeling secure in bed)

b. Change is Motion

Subjective Judgment: Experiencing a change of state

Sensoriomotor Experience: Moving

Primary experience: Experiencing the change of state that goes with the change of location as you move

c. Causes are Physical Forces

Subjective Judgment: Achieving results

Sensoriomotor Experience: Exertion of force

Primary experience: Achieving results by exerting forces on physical objects to move or change them

Given this, the metaphor posited by Goldberg (1995:88) in (12) is in fact a combination of the two primary metaphors in (13a) and (13b). Notice moreover that her analysis in (12) should also be modified by positing an additional inheritance link, the one having to do with the primary metaphor in (13c). In this sense, i.e., stricto sensu, Goldberg's (1995) use of the abstract CAUSE predicate in the basic or source domain structure in (12) is not quite appropriate: the replacement of the term "Caused-Motion Construction" by "Forced-Motion Construction" seems to be more justified.

Next consider the relevant minimal pair in (14), where the resultative construction in $(14 \mathrm{~b})$ can be seen to preserve the telic aspect of the forced-motion construction in (14a):

(14) a. Joe laughed the audience off the stage (in/*for ten seconds)

b. Joe laughed himself to death/to oblivion (in/* for an hour)

Indeed, the fact that those resultatives exemplified in (11b) and (14b) preserve a telic aspectuality follows from the more general claim alluded to by Gibbs's (2003:7) that the "metaphorical mappings preserve the cognitive topology of the embodied, image-shematic source domain" (cf. Lakoff's $(1990,1993)$ so-called Invariance Hypothesis). In the present case, there is a telos (or 'final goal') involved in the source domain of the forced-motion construction (cf. (14a)) that is mapped onto the target domain of the resultative construction (cf. (14b)): as pointed out by Goldberg (1995:84), "the resultative is a metaphorically interpreted goal phrase". It is then not surprising that resultative constructions are usually found to be telic: i.e., since forced-motion constructions are usually telic, 


\section{Jaume Mateu \& M. Teresa Espinal}

resultative constructions are predicted to be telic as well, by virtue of Lakoff's (1990, 1993) Invariance Hypothesis. ${ }^{2}$

Up to now we have been dealing with the somewhat easier or more predictable cases: i.e., the true resultatives, which are those whose aspect is telic. Next consider again the more interesting cases in (3), repeated in (15).
a. John laughed his butt off all day long/*in ten minutes
b. John worked his guts out all day long/*in ten minutes.

It must be recalled from section 2 that two non-trivial facts must be explained concerning the examples in (15): not only must we account for their conceptual interpretation (i.e., 'to act excessively'), but also their atelic aspect (i.e., their at first sight unexpected process or activity reading). Indeed, as emphasized above, we do not want to simply assume Jackendoff's $(1997,2002)$ stipulation concerning the former nor Glasbey's $(2003,2005)$ one concerning the latter. Rather, we want to motivate both interpretations (the meaning of 'excessively' and the atelic reading), and in order to achieve this goal we will use Lakoff \& Johnson's (1999) theory of conceptual metaphors.

On the other hand, although we do not provide experimental or psycholinguistic evidence for our present proposal, ${ }^{3}$ here we want to claim that metaphor can be shown to constrain aspect. This can better be shown in a non trivial way when dealing with the "exceptional" cases (e.g., fake resultatives), rather than when dealing with the usual ones (i.e., true resultatives). In fact, it should not be surprising that Glasbey's $(2003,2005)$ criticism of McGinnis's $(2002,2005)$ syntacticocentric treatment of aspect is mostly based on the existence of examples like those in (15), since - given McGinnis' hypothesis on the systematicity of aspect - only the accomplishment reading would be expected to emerge in (15), contrary to fact. However, as noted above, it seems to us that Glasbey's (2005) alternative solution of attaching the relevant aspectual reading (an atelic one in (15)) to the entire idiomatic phrases in the lexicon is not explanatory enough. Rather it seems to us that appealing to conceptual metaphor becomes unavoidable if one wants to account for (and not just stipulate) their atelicity.

To put it in the present terms, metaphor can be shown to constrain aspect in a non-trivial way precisely in those cases where metaphorical mappings do not appear to preserve the cognitive topology of the embodied, image-shematic source domain, i.e., in those cases where the so-called Invariance Hypothesis (Lakoff 1990, 1993) appears to be violated. In contrast, when dealing with "true" resultatives, aspectuality can be said to follow from the topology of the source

\footnotetext{
2 See Lakoff \& Johnson (1999) for the claim that such a hypothesis does not have a primitive status in their recent theory of conceptual metaphor.

${ }^{3}$ See Gibbs $(1994,1995$, i.a) for evidence showing how the meaning of idioms is metaphorically motivated.
} 


\section{Laughing Our Heads Off}

domain: the telos (i.e., the endpoint/final goal) in the source domain is mapped onto another one in the target domain (cf. (14)).

Given the previous discussion, let us try to motivate both stipulations involved in (15): i.e., the conceptual interpretation 'to act excessively' and its related atelic interpretation. Far from accepting the traditional claim that idioms are bearers of interpretive anomalies, we want to support the idea that they are conceived of as triggers of conceptual metaphors. In particular, the examples in (15) seem to involve a complex metaphor based on the well-established primary metaphor that conceives the body as a container, for extracting a part from this container is cognitively conceived of as an excessive, impossible action. This complex metaphor, which could be formulated as in (16), allows an interpretation according to which the exaggeration (i.e., the meaning of 'excessively') that emerges at the physical or source domain of the body is mapped as intensity onto the abstract or target domain of the relevant action: that is, acting excessively is conceptually motivated in terms of an excessive change undergone by the subject's body part.

\section{AN INTENSE ACTIVITY IS AN EXCESSIVE DETACHMENT / EXHAUSTION OF A BODY PART}

Given this, the fact that examples like (15a) and (15b) are conceptually interpreted as (roughly) 'John \{laughed/worked\} excessively' is assumed to be driven by the activation of the complex metaphor in (16). That is to say, the intensity meaning in (15a) is structured by an excessive (unreal) detachment undergone by the butt of the subject, while the intensity meaning in $(15 \mathrm{~b})$ is understood by means of an excessive (also unreal) exhaustion of the guts of the subject (e.g., notice that the same holds for the typical idiom to cry one's eyes out).

More generally, we claim that the particular complex metaphor in (16) is not but a subcase of the more general one represented in (17):

\section{AN INTENSE ACTIVITY IS AN EXCESSIVE CAUSED CHANGE OF LOCATION / STATE}

Our claim is that it is precisely the activation of the complex metaphor in (17) that accounts for the durative (i.e., atelic) aspect of examples like those in (15): the excessive change of location structured by a bounded path (out/off) is mapped onto the target domain as a more abstract unbounded intensity component. In other words, the two activities involved in the examples in (15) are conceptualized as so intense that they appear to lack boundaries; as a result of the activation of the complex metaphor in (17), there turns out to be no real endpoint involved in the final conceptual interpretation of the idiom, hence the non-resultative aspect of the semi-idiomatic constructions in (15).

Furthermore, (17) can also be argued to be involved in the process of understanding "fake resultatives" like the one in (18a), which has a typical durative (i.e., atelic) interpretation and contains a subset of adjectives (i.e., crazy or silly) 
initially conceptualized as final states of a caused change (cf. (12) above). We claim that the atelicity of (18a) follows from the fact that the excessive final endpoint/state associated to crazy/silly is conceptualized in such a way that the intense activity appears to lack boundaries. As above, as a result of the activation of the complex metaphor in (17), there turns out to be no final state involved in the final conceptual interpretation of the idiom, hence the typical non-resultative aspect of the semi-idiomatic construction in (18a).

(18) a. John laughed himself crazy/silly for an hour.

b. (?)John laughed himself crazy/silly in an hour.

On the other hand, concerning the telic interpretation in (18b), our claim is that the only complex metaphor involved is the typical one found in telic resultatives: i.e., A caused change of state is a forced motion/'change' of location, i.e., the very same one found in (11b) Joe kicked Bob black and blue or (14b) Joe laughed himself to death/to oblivion.

\section{Concluding Remarks}

So-called "fake resultative constructions" like We laughed our heads off have been assigned both a somewhat unexpected atelic interpretation (Glasbey 2003, 2005) and a conceptual meaning expressing intensity (Jackendoff 1997, 2002). Here we have shown that both associations must not be regarded as mere stipulations, but can be accounted for by examining a metaphorical process which is not syntactically transparent nor compositional.

In our previous work (e.g., Mateu \& Espinal 2007), we have claimed that a generative approach to the compositional meaning of idiomatic constructions must not be regarded as incompatible with the cognitive one presented here. We also leave it for further research to deal with Gibbs's (2003:14) concessive claim that "traditional propositional and high-dimensional approaches to semantics may not be entirely incompatible with an embodied meaning perspective". For the time being, we are persuaded that both perspectives (the generative one and the cognitive one) can provide interesting insights on the syntax and semantics of idioms.

\section{References}

Cappelle, Bert. 2005. Particles Patterns in English: A Comprehensive Coverage. Ph.D. diss., Katholieke Universiteit Leuven, Kortrijk.

Gibbs, Raymond W. 1994. The Poetics of Mind: Figurative Thought, Language, and Understanding. Cambridge: Cambridge University Press.

Gibbs, Raymond W. 1995. Idiomaticity and Human Cognition. In M. Everaert et al., eds., Idioms: Structural and Psychological Perspectives, 97-116. Hillsdale, NJ: Lawrence Erlbaum Associates. 


\section{Laughing Our Heads Off}

Gibbs, Raymond W. 2003. Embodied Experience and Linguistic Meaning. Brain and Language 84:1-15.

Glasbey, Sheila R. 2003. Let's Paint the Town Red For a Few Hours: Composition of Aspect in Idioms. In A. M. Wellington, ed., Proceedings of the ACL Workshop: The Lexicon and Figurative Language. Sapporo.

Glasbey, Sheila R. 2005. Aspectual Composition in Idioms. Ms., University of Birmingham.

Goldberg, Adele. 1995. Constructions. A Construction Grammar Approach to Argument Structure. Chicago: The University of Chicago Press.

Jackendoff, Ray. 1997. Twisting the night away. Language 73:534-559.

Jackendoff, Ray. 2002. Foundations of Language. Brain, Meaning, Grammar, Evolution. Oxford and New York: Oxford University Press.

Lakoff, George. 1990. The Invariance Hypothesis: Is Abstract Reason Based on Image-Schemas? Cognitive Linguistics 1:39-74.

Lakoff, George. 1993. The Contemporary Theory of Metaphor. In A. Ortony, ed., Metaphor and Thought, 202-251. Cambridge: Cambridge University Press.

Lakoff, George and Mark Johnson. 1999. Philosophy in the Flesh. The Embodied Mind and Its Challenge to Western Thought. New York: Basic Books.

Marantz, Alec. 1997. No Escape from Syntax. Don't Try Morphological Analysis in the Privacy of Your Own Lexicon. UPenn Working Papers in Linguistics 4(2):201-225.

Mateu, Jaume and M. Teresa Espinal. 2007. Argument Structure and Compositionality in Idiomatic Constructions. The Linguistic Review 24(1):33-59.

McGinnis, Martha. 2002. On the Systematic Aspect of Idioms. Linguistic Inquiry 33(4):665-672.

McGinnis, Martha. 2005. Painting the Wall Red for a Few Hours: A Reply to Glasbey (2003). Snippets 10. http://www.ledonline/snippets/

Nunberg, Geoffrey, Ivan Sag, and Thomas Wasow. 1994. Idioms. Language 70(3):491-538.

Jaume Mateu and M. Teresa Espinal

Departament de Filologia Catalana

Facultat de Filosofia i Lletres

Universitat Autònoma de Barcelona

E-08193 Bellaterra (Barcelona)

Spain

jaume.mateu@uab.cat teresa.espinal@uab.cat 